\title{
Certainty Factor for Online Game Addiction Scale Diagnosis - A Case Study of Informatics Student, University of Khairun
}

\author{
I Junaidi, $A$ Mubarak ${ }^{*}, S$ Kapita, $R$ Rosihan, and $H K$ Siradjuddin \\ Deaprtment of Informatics, Faculty of Engineering, Universitas Khairun, Ternate, Indonesia
}

\begin{abstract}
Online game addiction is the behavior of someone who wants to always play online games that lasts a long time and allows the individual concerned to not be able to control it so that it can have a negative impact that can have a negative impact on health and mental if too frequently play it. The aim of this study is to diagnose the online game addiction scale to students using the certainty factor algorithm. The level of online game addiction will be divided into three levels, namely: mild, moderate and severe addiction diagnoses. The calculation process starts from determining the weight value of each symptom and then determining the weight value of the user then calculating the weight value of each symptom with the user's weight value using the certainty factor method so as to produce how large the percentage level of online game addiction. The results showed that from a number of processed data the diagnostic results were obtained $13 \%$ of students with mild addiction, $37 \%$ of students with moderate addiction, $50 \%$ of students with severe addiction.
\end{abstract}

Keyword : Scale Diagnosis, Certainty Factor, Online Game Addiction

\section{Introduction}

The World Health Organization (WHO) has established a list of diseases in the International Statistical Classification of Diseases (ICD) and one of the diseases mentioned is gaming disease. The ICD is a list of medical classifications issued by the WHO containing a list of diseases and their symptoms, signs, and causes. ICD is an international standard for reporting diseases and health conditions, used by all health professionals around the world. In the latest version of ICD11, WHO pointed out that gaming addiction is a disorder caused by addictive behaviors or habits or addiction [8]. The negative consequences of online gaming addiction have prompted governments and health-care providers in South-East Asian countries to take the issue seriously and launch a series of initiatives to fightagaints and alleviate the problem. In South Korea, Online gaming addiction is regarded as a major public health concern, with up to 24 percent of children diagnosed with Internet addiction [6]. The negative impact of online games has been severe in several cities in Indonesia, such as teenagers in Banyumas experiencing mental disorders and youth in Palembang breaking into ATMs to play games. The classification of online games as a mental disease does not imply that they solely have a negative influence. Online games have a positive impact as well, such as increasing player concentration and encouraging teenagers to be smart, because online games require strong adolescent analytical skills and strategic planning in order to typically finish the game well. Whereas the disadvantage, the most concerning situation is when online game players have acted unlawfully excessively while playing online games, causing mental problems in the gamers.

The students of the informatics study program at University of Khairun is very familiar with the internet, in consequence students have a lot of opportunities to learn about and play online games. It has been observed that students play online games for an extended period of time, which can be harmful if they are included in the addiction scale, but the level of addiction experienced by informatics students in general is unknown.

The main purpose of this study is to diagnose the level of addiction of students in the informatics engineering study program using the factor certainty algorithm. The results of the addiction level diagnosis will be split into three levels of addiction, namely mild, moderate, and severe addiction.

\section{Literature}

\subsection{Online Game}

The network can be wired or wireless, and players can connect via LAN or the Internet.[3] Online gaming is one of the most popular leisure activities among many people. Some argue that playing video games can be used for a variety of purposes, including stress relief, challenge and competition, relaxation, enjoyment, social interaction, and even mentally escaping from the real 
world [1]. Online gaming is one of the most popular pastimes among most people, particularly teenagers, children, and students [5]. Online games are technically video games that can be played on Smartphones, Laptop, Computer, or any advanced technology with a connection through the internet or any other computer network available [2].

\subsection{Online Game Addiction}

Online gaming addiction is defined as a person's desire to continue playing online games that consume a significant amount of time, and it is possible that the individual in question is unable to control or control it [4].

\subsection{Certainty Factor}

Certainty factor expresses confidence in an event (fact or hypothesis) based on evidence or expert assessment. Certainty factor is defined as the following equation.

$\mathrm{CF}[\mathrm{H}, \mathrm{E}]=\mathrm{MB}[\mathrm{H}, \mathrm{E}]-\mathrm{MD}[\mathrm{H}, \mathrm{E}]$

Description:

$\mathrm{CF}[\mathrm{H}, \mathrm{E}]$ : certainty factors hypothetically influenced by evidence e are known with certainty.

$\mathrm{MB}[\mathrm{H}, \mathrm{E}]$ : measure of belief against hypothesis $\mathrm{H}$, if given evidence $\mathrm{E}$ (between 0 and 1 )

MD: Measure of Disbelief

Q: Probability.

E: Evidence (Events/Facts)

Certainty Factor for rules with single premise / symptom (single premise rules):

\section{CFSymtomp $=\mathrm{CF}[$ user $] * \mathrm{CF}[$ expert $]$}

If there are rules with similar conclusions(similiary concluded rules)or more than one symptom, then $\mathrm{cf}$ is then calculated by equation:

\section{CFcombine $=$ CFold + CFsymptom $*(1-$ CFold $)$}

As for calculating the percentage against the disease, the equation is used:

CFpersentase $=$ CFcombine $* 100$

\section{Result}

\subsection{Data Set}

In collection of primary data, the author use observation and interview method. The author uses a questionnaire to collect data from respondents. and collects 100 amount of data that can be used as data sets for analysis.

\subsection{Designing Certainty Factor}

What needs to be designed in the certainty factor technique is the determination (expert $\mathrm{CF}$ ) as the certainty value given by the expert to a rule, symptom data, and expert $\mathrm{CF}$ value based on the expert's scientific journal literature results. Based on the results of the scientific journal literature [7] with a psychiatrist as an expert in his research. Can be seen in the following table:

Table 1. Expert CF Value

\begin{tabular}{|l|l|l|}
\hline No & Indication & $\begin{array}{l}\text { CF Expert } \\
\text { Value }\end{array}$ \\
\hline 1 & G1 & 0,2 \\
\hline 2 & G2 & 0,3 \\
\hline 3 & G3 & 0,15 \\
\hline 4 & G4 & 0,45 \\
\hline 5 & G5 & 0,4 \\
\hline 6 & G6 & 0,6 \\
\hline 7 & G7 & 0,65 \\
\hline 8 & G8 & 0,85 \\
\hline 9 & G9 & 0,8 \\
\hline 10 & G10 & 0,8 \\
\hline
\end{tabular}

Description:

G1: Often play games

G2: Life pattern is starting to become irregular/disturbed (forgetting to eat, forgetting to take a shower, not doing homework)

G3: Lazy to do anything other than play games

G4: Very enthusiastic when asked about the game

G5: Can't concentrate when doing anything except playing games

G6: Often sleepy due to playing too many online games

G7: Easily emotional when playing online games

G8: Often imitates game characters in real life

G9: Disconnected from social life (prefers playing games over interacting with people)

G10: Willing to spend a lot of money to play the game

After the identification of the Expert CF value, we will turn to the identification of the User CF value, which will be set by the user himself.

Tabel 2. CF User Value

\begin{tabular}{|c|c|}
\hline Description & $\begin{array}{c}\text { CF User } \\
\text { Value }\end{array}$ \\
\hline Unconfident & 0 \\
\hline Confident & 0,8 \\
\hline
\end{tabular}

\subsection{The rules of the online gaming addiction diagnosis}

The following step is to establish the rules that will be used to assess the level of online game addiction. The rules of the online gaming addiction diagnostic system to get addiction results:

- R1: IF percentage of addiction 1\%-64\% then mild addiction 
- R2: IF addiction percentage $65 \%-97 \%$ then moderate addiction

- R3: IF the percentage of addiction $\geq 97 \%$ then severe addiction

\subsection{Test Result}

On the test results using the data that has been collected, the results are shown in the diagram of the results of the diagnosis that has been carried out using the certainty factor.

The percentage of symptoms encountered by students of informatics study program can be seen in the diagram, the percentage of symptoms experienced can be shown in figure 1 based on the results of tests that have been completed in the informatics program.

the percentage of symptoms experienced by
students

$G \%$

Fig.1. Symptom Percentage Diagram

The percentage level of addiction of online games experienced by Informatics Study Program students can be seen in figure 2 .

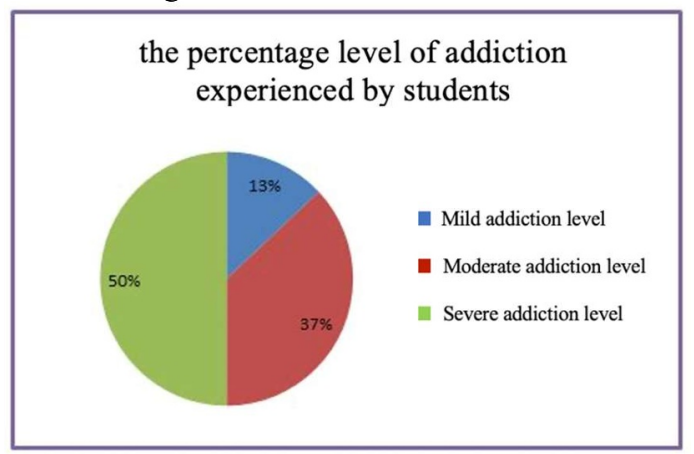

Fig.2. Online game level addiction scale

Figure 2 shows the percentage of online game addiction as a result of the analysis. It shows about 13 percent experiencing mild addiction, 37 percent experiencing moderate addiction and 50 percent experiencing severe severe addiction.

\subsection{Deployment}

The results of the use of the certainty factor approach are then built into applications that others can use to assess their level of online game addiction.

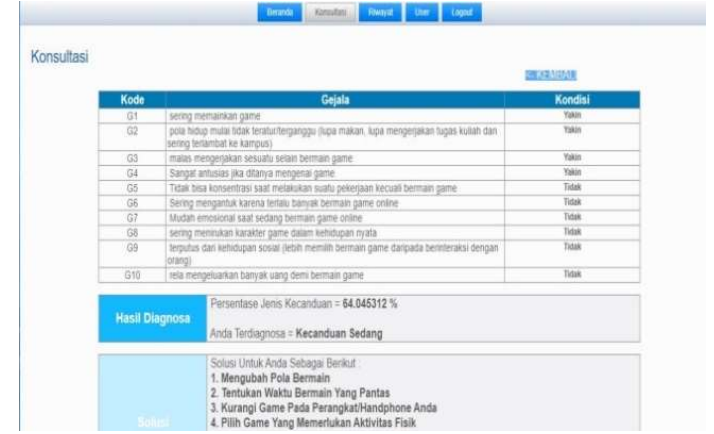

Fig.3. Consultation page

Figure 3 shows a consultation page that can be used to input the symptoms experienced by respondents. This page also offers information about the level of addiction encountered, as well as recommendations based on the results acquired.

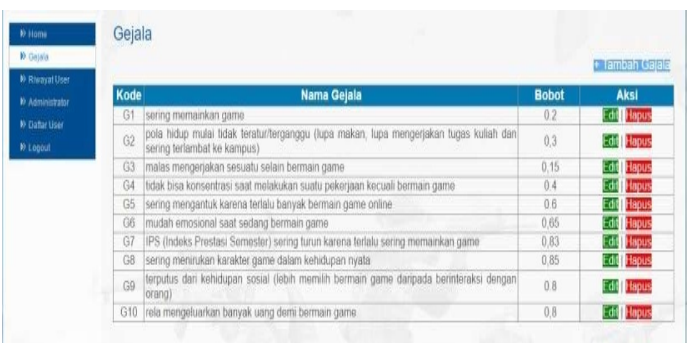

Fig.4. List of Symptomps

Figure 4 depicts the symptom data that was used as a variable in the diagnosis. This symptom has been recorded in the database and can be accessed via the consultation page by respondents. These symptoms can be added and deleted based on the factors that will be used.

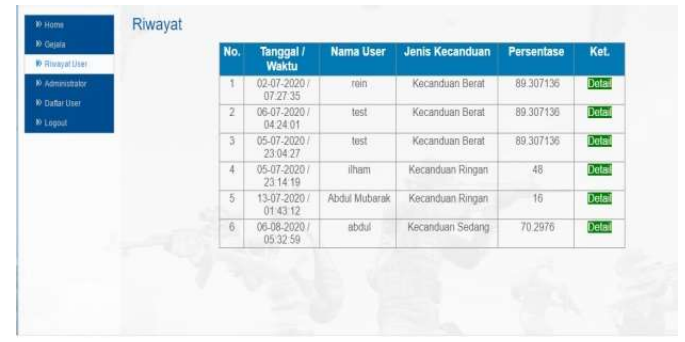

Fig.5. History of test

Figure 5 depicts a list of users who took the test, as well as the results of the addiction test they completed. There is also a link on this page to view the specifics of the diagnostic findings that have been performed.

\section{Conclusion}

Certainty factor method was successfully applied to the system of online gaming addiction diagnosis, the application of certainty factor method was successfully applied to some students with three levels of addiction, namely mild addiction with a percentage of addiction 
$13 \%$, moderate addiction with a percentage of $37 \%$ and severe addiction with a percentage of $50 \%$.

The results of this study show that the certainty factor method has successfully diagnosed the level of addiction in Students of Khairun University Informatics Study Program.

\section{References}

1. Dumrique, DO, Castillo, J G, Online Gaming: Impact on the Academic Performance and Social Behavior of the Students in Polytechnic University of the Philippines Laboratory High School, 4th International Research Conference on Higher Education Vol. (2018).

2. Childnetinternational. Online gaming: An introduction to parents and carers, (2017).

3. Chen. Tsung Teng, Online Games: Research Perspective and Framework, ACM Computers in Entertainment, Vol. 11, No. 4, Article 3, Publication date: December, (2014).

4. Imanuel, N. 2009. Personality Profile Overview in Teens Who Are Addicted to Online Games and Who Are Not Addicted to Online Games. Thesis published. Depok: Faculty of Psychology UI.

5. Kuss, Daria J. and Mark D. Griffiths. (2012). Adolescent online gaming addiction. Education and Health, 30 (1), 15-17.

6. Kuss, Daria J, Internet gaming addiction: current perspectives, Psychology Research and Behavior Management 2013:6 125-137.

7. Sianturi, the system of experts diagnoses the Indication of online gaming addiction using certainty factor method". Pelita imformatika Budi Darma, Vol 7, no 3, August (2014).

8. WHO, Addictive behaviours: Gaming disorder, $14^{\text {th }}$ September, (2018). 